\title{
Perfil, formação profissional e noção de política sindical de metalúrgicos de Criciúma e Sul Catarinense
}

\section{Profile, vocational training and policy concept of trade union of Criciúma metals and South Catarinense}

Gilvan Felipe Teixeira de França - Mestrando no Programa de Pós-Graduação em Desenvolvimento Socioeconômico da Universidade do Extremo Sul Catarinense. Membro do grupo de pesquisa "História Econômica e Social de Santa Catarina. E-mail: gilvandefranca@gmail.com

João Henrique Zanelatto - Professor da Universidade do Extremo Sul Catarinense, atuando nos Cursos de História e de Economia e no Programa de Pós-Graduação em Desenvolvimento Socioeconômico. Pós-Doutor e Doutor em História, Membro do grupo de pesquisa História Econômica e Social de Santa Catarina. E-mail: jhz@unesc.net

\section{Resumo}

O município de Criciúma, situado no Sul Catarinense, teve sua economia centrada por várias décadas na exploração do carvão mineral. Entretanto a partir da década de 1950 o município experimentou um processo de diversificação econômica. Um dos setores desta diversificação foi o metalúrgico que está presente em vários municípios do Sul Catarinense. Com o crescimento deste setor, o número de trabalhadores nesta atividade se eleva. Este artigo tem por objetivo analisar o perfil atual, a formação profissional e a noção de política sindical dos trabalhadores das indústrias metalúrgicas de Criciúma e do Sul Catarinense.

\section{Palavras-chave}

Trabalhadores. Metalúrgicos. Criciúma. Brasil.

\begin{abstract}
The municipality of Criciuma located in the southern Santa Catarina had its economy based for decades in the exploration of coal. But from the 1950s the city's economy experienced a process of economic diversification. One of the sectors of this diversification was the metalworker who is present in several municipalities of Santa Catarina south. With the growth of this sector, also increased the number of workers in this activity. Thus, the article aims to address the profile, training and concept of political union of workers of metallurgical industries of Criciuma and Santa Catarina south.
\end{abstract}

\section{Keywords}

Workers. Metallurgical. Criciuma. Brasil. 


\section{INTRODUÇÃO}

Analisar os dados da pesquisa Perfil e formação profissional dos funcionários da indústria metal mecânica de Criciuma e Região, composta por mostra quantitativa de 1.147 entrevistas realizadas entre setembro e outubro de 2013 pelo Instituto de Pesquisa Socioeconômica Aplicada (Ipese) da Universidade do Extremo Sul Catarinense (Unesc), é o objetivo central do presente artigo. A análise foi embasada nos princípios de Hobsbawm (1995; 2000; 2005), que estudou o mundo do trabalho, a origem e o desenvolvimento do capitalismo, a luta de classes como fator fundamental para o processo histórico e, sobretudo, elaborou a história "de baixo para cima" e a teoria a partir da prática histórica. A pesquisa foi contratada pelo Sindicato dos Trabalhadores nas Indústrias Metalúrgicas, Mecânicas e de Material Elétrico de Criciúma e Região, e cedida para este trabalho acadêmico por seu então presidente, Oderi Gomes.

As preocupações da representação dos trabalhadores têm por base o cenário descrito por Hobsbawm (1995, p. 404), que pode se repetir de forma ampliada cada vez mais, com o avanço das tecnologias e da busca incessante da classe patronal pelo lucro.

A tragédia histórica das Décadas de Crise foi a de que a produção agora dispensava visivelmente seres humanos mais rapidamente do que a economia de mercado gerava novos empregos para eles. Além disso, esse processo foi acelerado pela competição global, pelo aperto financeiro dos governos, que - direta ou indiretamente - eram os maiores empregadores individuais, e não menos, após 1980, pela então predominante teologia de livre mercado que pressionava em favor da transferência de emprego para formas empresariais de maximização de lucros, sobretudo para empresas privadas, que, por definição, não pensavam em outro interesse além do seu próprio, pecuniário. (HOBSBAWN, 1995, p. 404)

Conforme o caderno de resultados consultado, a pesquisa teve o "objetivo de verificar a necessidade de capacitação e relação da formação profissional versus ocupação, bem como a percepção dos funcionários em relação ao nível tecnológico da indústria local". Quanto à metodologia, o tipo de pesquisa foi quantitativa, o instrumento de coleta dos dados em questionário estruturado e o universo pesquisado foi integrado por trabalhadores dos horários diurnos de um grupo de empresas relacionadas pela diretoria do sindicato profissional, nos municípios de maior prevalência de indústrias do setor. 


\section{TRAJETÓRIA E CRESCIMENTO DA INDÚSTRIA METALÚRGICA}

No caderno dos resultados da pesquisa com os trabalhadores metalúrgicos, Oderi Gomes, presidente do Sindicato, justificou a iniciativa, "nunca tínhamos realizado pesquisa na categoria, e queríamos ter uma radiografia para podermos conhecer melhor os metalúrgicos, com isso poder ver os erros e acertos e corrigilos". Para ele, os pontos mais importantes da pesquisa foram os indicativos de nível de formação, de idade dos trabalhadores, do tempo de profissão e de empresa, o padrão de vida dos profissionais e as formações familiares.

Gomes ressaltou que os resultados da consulta foram apresentados e debatidos com sindicatos patronais do setor, escolas profissionalizantes e universidades de Criciúma e região. O principal objetivo, neste sentido, foi o de "direcionar esforços para qualificar e diversificar a formação de profissionais, investindo no desenvolvimento de tecnologias de ponta para atender todos os setores e tentar acabar ou diminuir as atividades penosas causadoras de doenças do trabalho". A iniciativa, desta forma, mostra a preocupação dos dirigentes sindicais em conhecer com maior profundidade a categoria.

Segundo Goularti Filho e Livramento (2004), na região sul de Santa Catarina, as primeiras notícias de organização e mobilizações trabalhistas datam de 1891, quando trabalhadores da Estrada de Ferro Dona Tereza Cristina pararam em protesto pelos baixos salários e voltaram a parar em 1912, 1928, 1934 e 1939.

É dessa época o primeiro registro de um movimento organizado de mineiros na região. Em 1920, conforme Goularti Filho e Livramento (2004), mais de 300 mineiros da Companhia Brasileira Carbonífera Araranguá (CBCA) pararam para exigir salários atrasados e aumento salarial. Os trabalhadores do setor, contudo, somente se organizaram com a fundação da Associação Profissional dos Trabalhadores na Indústria da Extração do Carvão de Criciúma em 27 de fevereiro de 1944, transformada em sindicato em maio de 1945. Em agosto daquele mesmo ano, foram os mineiros da Companhia Próspera que fizeram greve.

Os mineiros de Criciúma e região se organizaram de tal forma que suas mobilizações por salários e condições de trabalho acabaram fazendo história na cidade e região, pela forma dos enfrentamentos. A partir da organização dos mineiros, sindicatos de outras categorias profissionais começam a ser fundados na cidade, a iniciar pelos comerciários e ceramistas, segmentos que começavam a despontar na cidade e região e dos metalúrgicos, em 1962.

A economia de Criciúma e região vinha se diversificando desde a década de 1940, com o surgimento das primeiras indústrias cerâmicas de revestimento. 
Na visão de Teixeira (1996), em "Os donos da cidade", famílias tradicionais deixaram até de investir seus recursos em minas de carvão, buscando alternativas mais rentáveis e menos turbulentas.

As próprias empresas mineradoras se diversificam, algumas, inclusive abandonam a mineração e passam a dar prioridade a outros ramos de atividade mais lucrativas e menos dependentes das oscilantes políticas governamentais e cíclicas crises do carvão. $\mathrm{Na}$ nova configuração econômico-empresarial temos um cenário diferente na cidade, agora caracterizada pela diversificação da economia e o pluralismo político e cultural (TEIXEIRA, 1996, p. 115).

O desenvolvimento da diversificação da economia no sul de Santa Catarina, paralelo ao período em que a indústria de extração de carvão representava a maior parte dos empregos e recursos produzidos na região, fez surgir iniciativas no setor metal-mecânico. Indústrias foram criadas para produzir peças e equipamentos necessários à mineração de carvão e à indústria cerâmica. Além disso, a agricultura, desde o início da colonização da região, continuava sendo fonte de demandas. Sobre o processo de diversificação e em especial do crescimento das indústrias metalúrgicas, Goulart explica que:

Muitas metalúrgicas da região que sugiram nos anos 1950 e 1960 para atender às minas ou à agricultura ainda estão em atividade e tiveram origem em pequenas oficinas ou no comércio. A metalúrgica mais antiga da região é a Metalúrgica Spillere, em Nova Veneza, fundada em 1946, que começou suas atividades funcionando com uma caldeira a vapor, produzindo implementos agrícolas à tração animal (GOULARTI FILHO, 2003, p. 48).

A expansão das metalurgias foi também descrita por Santos:

Dezenas de pequenas e médias empresas surgiram nas décadas de 1970 e 1980, a partir de Criciúma, para atender a demanda de peças, componentes e equipamentos utilizados na mineração e na indústria cerâmica, que, em 1988, já absorvia mais de quatro mil empregos. Hoje, a indústria metalúrgica da região carbonífera, além de ser capaz de produzir fábricas inteiras para o setor cerâmico, bem como a maioria dos equipamentos utilizados na mineração das minas de carvão, vem exportando pacotes inteiros para países da América Latina e da África. Unidades cerâmicas completas vêm sendo implantadas no Peru, no Suriname e no Zâmbia por indústrias locais (SANTOS, 1995, p. 127).

A realidade dos trabalhadores do setor é revelada pelo Sindicato dos Trabalhadores nas Indústrias Metalúrgicas, Mecânicas e de Material Elétrico de Criciúma, em sua página oficial na internet (www.sinmetal.org.br). O órgão 
de representação foi fundado em 5 de maio de 1962 e conta com cerca de 3,5 mil associados, sendo que em sua base territorial atuam aproximadamente 10 mil trabalhadores, em 29 municípios. Os trabalhadores metalúrgicos desde 1979 renovam anualmente uma convenção coletiva de trabalho, contando com conquistas como estabilidade pré-aposentadoria, horas extras com adicional de até $100 \%$, adicional noturno de 30\%, entre outros direitos ampliados previstos na CLT.

O Jornal da Manhã, um dos jornais diários de Criciúma, em sua edição 9128, de 28 de julho de 2014, publicou ampla reportagem, intitulada "Indústria do Sul caminha para o desenvolvimento". O trabalho tem como base de informações o Programa de Desenvolvimento da Indústria Catarinense para os próximos anos (PDIC, 2022), promovido pela Federação das Indústrias do Estado de Santa Catarina (Fiesc). Uma das pautas relata a atual situação da indústria metal-mecânica de Criciúma e região. O jornal constrói a reportagem incluindo entrevista com o presidente do Sindimetal, empresário Guido Búrigo. Ele informa que o sindicato patronal conta com 100 indústrias associadas, mas na região carbonífera e no extremo sul catarinense, sua área de atuação, existem em torno de 1,5 mil empresas, que geram mais de 10 mil empregos e faturamento superior a $\mathrm{R} \$ 3$ bilhões/ano.

\section{PERFIL SOCIOECONÔMICO DOS TRABALHADORES}

Para apurar o perfil dos trabalhadores metalúrgicos de Criciúma e região a diretoria do sindicato da categoria relacionou 17 empresas, nos municípios de Araranguá, onde foram ouvidos 165 trabalhadores, Criciúma com 233 entrevistas, Içara com 171 consultas, Morro da Fumaça com 52, Nova Veneza com 121, Orleans com 116, Siderópolis com 66 e Urussanga com 223 questionários preenchidos. As empresas Ibrap Indústria Brasileira de Alumínio e Plástico, de Urussanga, com 152 trabalhadores pesquisados e Industrial Pagé, de Araranguá, com 165, foram os locais de trabalho com maior quantidade de entrevistas realizadas. Dos 1.147 questionários preenchidos apenas 138 eram de trabalhadoras, configurando na maior presença de homens nos locais de trabalho. Das entrevistadas, 86 eram de Urussanga, o maior contingente em um mesmo município.

Em relação à renda familiar apurada entre os 1.147 trabalhadores, apenas quatro declararam ter faturamento superior a $\mathrm{R} \$ 13.560,00$, sendo dois em Nova Veneza e os demais em Criciúma e Morro da Fumaça. Dos entrevistados, $45,77 \%$, revelou ter renda familiar entre $\mathrm{R} \$ 1.356,00$ e $\mathrm{R} \$ 2.712,00$, um total de

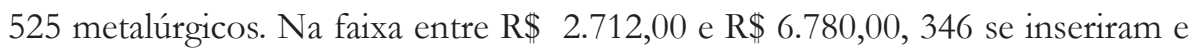
com renda familiar até $\mathrm{R} \$ 1.356,00$, se declararam 234 trabalhadores. 
Por faixa etária, o maior contingente de profissionais do ramo metal mecânico de Criciúma e região têm entre 21 e 45 anos de idade, com 310 entrevistados, representando 27,03\% do total. Até 20 anos foram ouvidos 166 trabalhadores, seis com idades entre 56 e 60 anos e sete com mais de 60 anos. Dos pesquisados, 471 são solteiros, 140 vivem em união estável e 490 são casados. Do total, 592, ou 51,61\% da amostra, não têm filhos; 272 (23,71\%) são pais de filhos únicos e 185 têm dois filhos (16,13\%). Entre os 1.147 pesquisados, seis têm cinco filhos, dois têm seis e três declararam ter sete filhos.

A pesquisa também buscou informações sobre o endividamento dos trabalhadores e suas famílias. Do total, 684 metalúrgicos, 59,63\%, informaram ter "algum tipo de financiamento" e 456 (39,76\%) não. Entre os bens financiados lidera o de carros, com 392 citações e de habitação, com 172 ocorrências, respectivamente $57,31 \%$ e $25,15 \%$, do total. A pesquisa constatou que 144 trabalhadores têm empréstimo consignado; 98 financiaram motos e que em Urussanga um trabalhador metalúrgico tem financiamento de trator. Cinco dos entrevistados informaram considerar "financiamento" o custo de manutenção de curso universitário e 57 adquiriram eletrodomésticos e utensílios domésticos por financiamento.

A longevidade profissional dos trabalhadores e o tempo de carreira na mesma empresa foram pesquisados. A maior quantidade de ouvidos, 313, estão no mercado de trabalho de 12,1 a 24 anos, representando 27,29\% do total. Em segundo lugar aparecem os que estão entre 6,1 a 12 anos, 26,24\%, seguido de ocorrências de 22,14\% de 3,1 a 6 anos. A menor quantidade é dos que estão até a um ano no mercado de trabalho, 56 trabalhadores, 4,88\% do total. À pergunta "quantos anos você trabalha nessa empresa?", 411 entrevistados responderam que era até um ano, representando 35,83\% do total; 29,82\% estão até três anos na empresa, 17,61\% de 3,1 a 6 anos, 10,46\% de 6,1 a 12 anos, 4,71\% de 12,1 a 24 anos e cinco trabalhadores declararam estar há mais de 24 anos na mesma empresa, o equivalente a $0,44 \%$ do total pesquisado.

\section{DA FORMAÇÃO ESCOLAR DA CATEGORIA}

Segundo o relatório de pesquisa desenvolvido pelo Ipese/Unesc, o nível escolar dos entrevistados com maior prevalência, 43,77\%, é de trabalhadores com ensino médio completo, com 502 questionários. O segundo mais indicado é o índice de 19,44\% para os trabalhadores com ensino médio incompleto. Do total, $4,53 \%$, com 52 respostas, informou ter ensino superior completo e 13,16\% curso universitário incompleto. Do total, 10,72\% tem ensino fundamental completo e 
$7,41 \%$ fundamental incompleto. Destes dados o relatório apresenta o seguinte gráfico, na página 15 (Gráfico 1).

Gráfico 1 - Nível escolar por município

\section{NÍVEL ESCOLAR POR MUNICÍPIO}

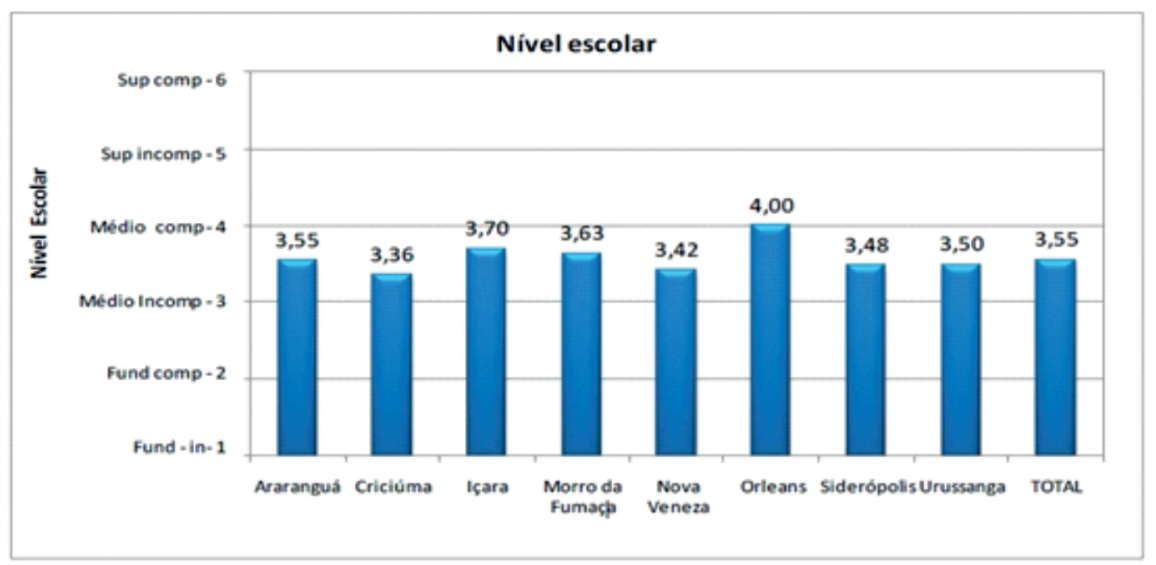

Fonte: Caderno (2013)

Entre os 1.147 entrevistados, 552, ou 48,13\%, responderam não terem tido formação profissional. Entre os pesquisados, 263, ou 22,93\%, tiveram sua formação profissional na Associação Beneficiente da Indústria Carbonífera de Santa Catarina (SATC); 99 no Bairro da Juventude do Padres Rogacionistas (8,63\%), 91 no Serviço Nacional de Aprendizagem Industrial (Senai) (7,93\%), Universidade do Extremo Sul Catarinense (Unesc) e no Centro Universitário (Unibave) com 30 citações cada (2,62\%), e 18 no Instituto Federal de Santa Catarina (IFSC), com 1,57\% de frequência. Outros 53 estabelecimentos de ensino formaram profissionalmente 120 dos entrevistados. Entre os citados destaca-se a própria empresa, com 23 ocorrências, o Sesi com 14 e a Esucri com 10.

Entre os trabalhadores que informaram terem realizado cursos de qualificação profissional, o de soldagem teve 64 citações, seguido de Mecânica (54), operador de empilhadiera (34), Eletromecânica (27), técnico em Mecânica e torneiro mecânico (26), Informática (25), Administração (23), Metrologia (21), Desenho Técnico (18), Elétrica e Interpretação de Desenho Mecânico (17), ajustador mecânico (15), Eletrotécnica (14), Contabilidade e ponte rolante (12), Engenharia de Produção, Logística, Processos Gerenciais e técnico de Segurança do Trabalho (10). As demais foram inferiores a dez citações, com um total de 97 respostas diferentes de cursos realizados. 
A pesquisa apresenta uma impressionante quantidade de funções nas empresas em que atuam os trabalhadores ouvidos. Entre os questionários preenchidos, 80 era de ocupantes da função auxiliar de produção, seguido de montador (76), operador (71), soldador (54), operador de CNC (46), almoxarifado (33), pintor (29), torneiro (28), embalador (26), eletricista (20), modelista (19), expedição (17), alimentador (14), ajudante de produção (14), ajudante geral (14), auxiliar de produção (13) rebarbação (13), encarregado (12), forneiro (12), logística (11), operador de empilhadeira (11) e programador de torno CNC (10). Com menos de dez citações aparecem um total de 240 outras funções.

Mais de um terço dos trabalhadores do ramo metalúrgico não atuam em sua área de formação, constatou a pesquisa desenvolvida pelo Ipese/Unesc. A esta questão 367 entrevistaram responderam que trabalham em função diferente de sua formação. Atuam, sim, completamente em suas funções 29,56\%, 339 respostas, e em parte estão 265 profissionais, ou 23,10\% do total pesquisado. Deste total, 717 trabalhadores $(62,51 \%)$ acreditam que têm pespectiva reais de crescimento profissional, 268 (23,37\%) acreditam em parte, e 75 (6,54\%) não têm perspectivas de crescimento profissional. O maior contingente dos que têm perspectivas de crescimento profissional está na faixa etária de 21 a 25 anos, com 218 citações, ou 70,32\% do total.

Para os metalúrgicos de Criciúma e região, conforme a pesquisa, estudar é importante. Dos entrevistados, $916(79,86)$ afirmaram que têm pretensão de continuar estudando, enquanto 16,83 \% (193 respostas) não têm esta pretensão. Não responderam 38 trabalhadores, 3,31\% do total. Dos que afirmaram positivamente à continuidade dos estudos, 58,85\% pretendiam fazer isto no próximo ano e 10,64\% no ano posterior. Novamente os mais jovens (de 21 a 25 anos) compõem a faixa etária que quer continuar estudando.

À pergunta "você sente necessidade de capacitação para exercer suas atividades?", 625 entrevistados afirmaram que "sim", 54,49\% do universo total e 445 deram resposta negativa ao questionamento. Não souberam responder 77 dos entrevistados. Do grupo de 625 trabalhadores que sentem necessidade de capacitação para o exercício profissional, 190 (61,29\%) são da faixa etária de 21 a 25 anos.

Satc com 223 citações, Unesc com 136 e o Sesi com 46, são as instituições preferidas para os estudos, aponta a pesquisa. O curso mais desejado pelos trabalhadores metalúrgicos é o de Engenharia Mecânica, com 60 citações, seguido de Mecânica com 50 e Engenharia de Produção com 28. Eletro Mecânica e Engenharia Civil empataram com 25 indicações de preferência, seguidos de Programação e Operação de Torno CNC (21), ensino médio (18), 
técnico de Segurança do Trabalho (17), Soldagem (16), Metalurgia (15), Direito e pós-graduação (14), Processos Gerenciais (12), Educação Física (11), Torno Mecânico (10). Outras 73 indicações de cursos foram feitas, todas com menos de dez indicações.

A pesquisa também observou a percepção do nível de tecnologia em relação à empresa em que o trabalhador atua. Dos entrevistados, 68,70\% consideram que "existe algo grau de tecnologia" em seus locais de trabalho. Para 81,69\%, "existe a necessidade de investir em tecnologia", 70,79\% afirmam que "a empresa investiu de forma significativa em tecnologia nos últimos dois anos", 66,96\% entende que "existe a constante inovação em máquinas e equipamentos", 65,74\% percebe que "existem constante desenvolvimentos de novos métodos de trabalho" e 73,32\% que "existe constante lançamento e/ou melhoria de produtos".

As questões e respostas resultaram na elaboração de gráfico entre as opiniões dos entrevistados sobre a percepção do nível de tecnologia em relação a empresa em que trabalha, apresentado na página 81 do relatório (Gráfico 2).

Gráfico 2 - Opiniões dos entrevistados sobre a percepção do nível de tecnologia em relação à emprtesa em que trabalham

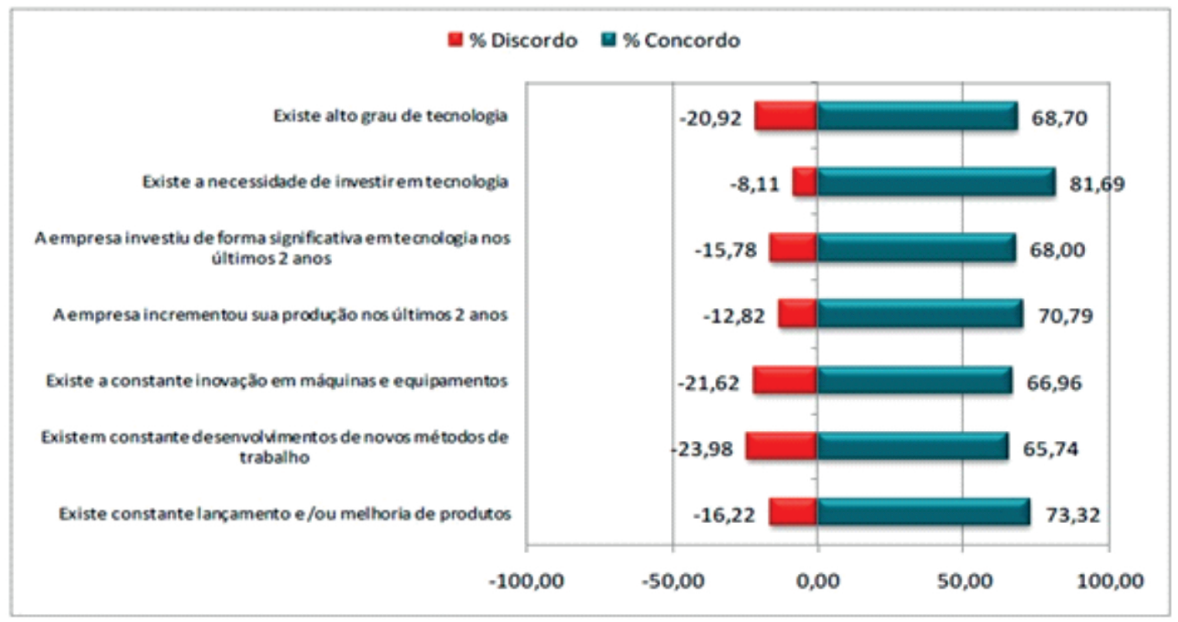

Fonte: Caderno (2013)

\section{SINDICATO E POLÍTICA NA PERSPECTIVA DOS TRABALHADORES}

A última etapa da pesquisa se destinou a prospectar as opiniões dos trabalhadores em relação a aspectos relacionados à política-partidária e ao desempenho da diretoria do sindicato. $\mathrm{O}$ resultado apresentado no relatório 
em relação ao envolvimento de dirigentes sindicais com a política partidária surpreendeu a diretoria. Segundo Oderi Gomes, "ficamos surpresos e tiramos como encaminhamento convencer os trabalhadores da importância do envolvimento no processo político e iremos continuar o processo e convencimento da categoria". Gomes foi candidato a deputado estadual, pelo PCdoB, em 2014, ficando como suplente de seu partido.

O primeiro questionamento aos trabalhadores metalúrgicos foi "de uma maneira geral, o sr(a) gosta ou não de política?” A maioria, 55,45\%, não gostam. Responderam que gostavam 35,57\% e não sabiam 8,98\%. Surpreendeu, também, que entre os que não gostam, o maior contingente, 139 respostas, são de trabalhadores de Criciúma, ou seja, 59,66\% daqueles que dizem não gostar de política. $\mathrm{Na}$ "frequência relativa", no entanto, o município que concentra o maior índice de trabalhadores que não gosta de política é Morro da Fumaça, com $63,46 \%$ deste grupo.

O envolvimento do sindicato dos trabalhadores com a política partidária é rejeitada pela maioria dos entrevistados pela pesquisa e resultou em gráfico apresentado na página 90 do relatório do Ipese (Gráfico 3).

Gráfico 3 - Envolvimento do sindicato dos trabalhadores com a política partidária

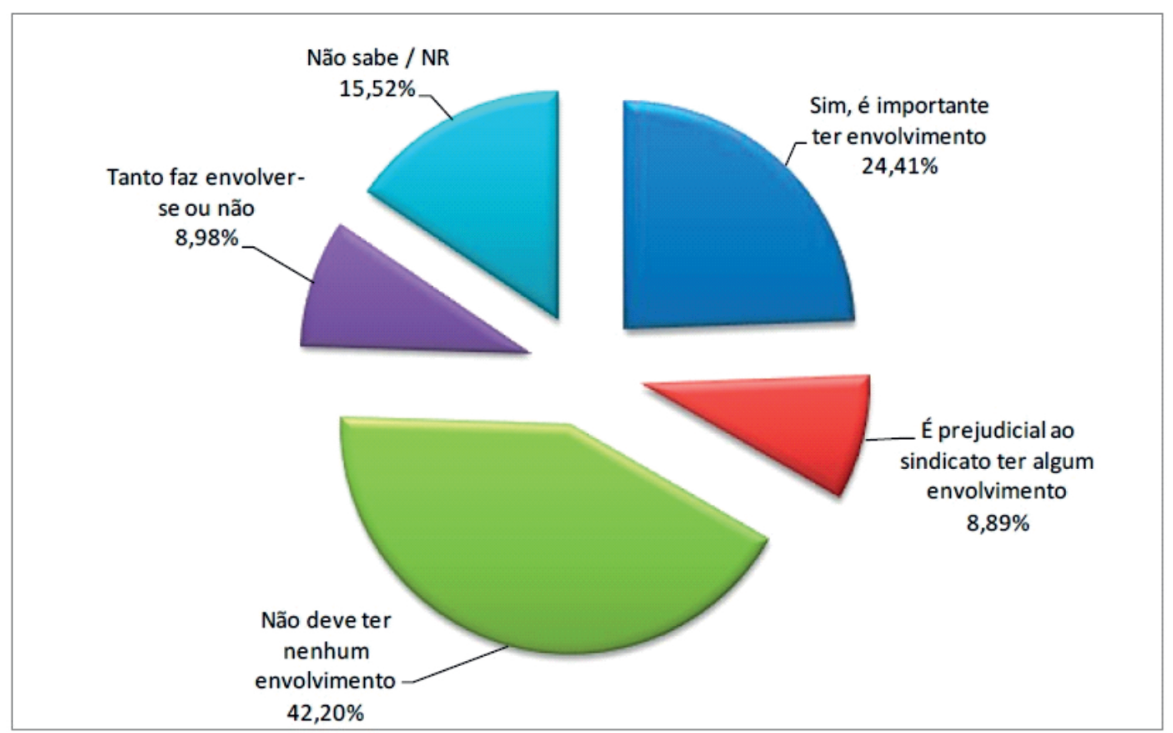

Fonte: Caderno (2013)

Dos entrevistados, 36,36\% consideram a gestão do sindicato como "ótimo/ bom", 36,09\% classificam como regular, 7,76\% ruim e 4,53\% péssimo. Não souberam responder $15,26 \%$. Os pesquisadores solicitaram que os entrevistados 
dessem nota de zero a dez para a administração do sindicato e no total, as notas de sete para cima foram 26,16\%, 21,45\%, 6,10\% e 3,23\%. Entre os entrevistados, 122 não responderam, totalizando $10,64 \%$ de trabalhadores que se abstiveram de avaliar a atuação da administração do sindicato que os representa. $\mathrm{Na}$ "frequência absoluta", a nota zero foi dada em maior quantidade de trabalhadores em Orleans, com dez respostas e a maior quantidade de notas dez ocorreram em Criciúma, com oito respostas. Ao final da avaliação geral, a nota média, excluídas as "não respostas", ficou em 6,59.

A questão resultou em quadro que está disponível na página 102 do relatório (Tabela 1$)$.

Tabela 1- Atribuição de notas pelos entrevistados à administração do sindicato

\begin{tabular}{|c|c|c|c|c|c|c|c|c|c|}
\hline $\begin{array}{l}\text { FREQUÊNCIA } \\
\text { RELATIVA (\%) }\end{array}$ & 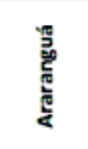 & 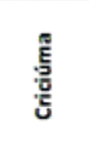 & $\underline{\underline{\mathrm{E}}}$ & 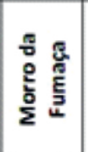 & 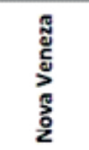 & 幽 & $\begin{array}{l}\text { 뜸 } \\
\frac{}{\circ} \\
\text { 흔 }\end{array}$ & 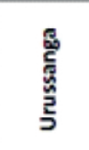 & 㐫 \\
\hline 0 & 3,03 & 3,00 & 0,58 & & 2,48 & 8,62 & & 1,35 & 2,53 \\
\hline 1 & & 0,86 & 0,58 & & & 0,86 & & 1,35 & 0,61 \\
\hline 2 & 1,21 & 1,29 & & 3,85 & 0,83 & 1,72 & 1,52 & 2,24 & 1,39 \\
\hline 3 & 1,21 & 2,15 & 2,34 & 3,85 & 3,31 & 4,31 & & 2,69 & 2,44 \\
\hline 4 & 4,85 & 3,86 & 2,92 & 9,62 & 2,48 & 0,86 & 1,52 & 1,79 & 3,14 \\
\hline 5 & 9,70 & 15,02 & 9,36 & 13,46 & 7,44 & 7,76 & 12,12 & 8,07 & 10,29 \\
\hline 6 & 12,73 & 16,31 & 9,36 & 1,92 & 14,05 & 13,79 & 9,09 & 10,31 & 12,03 \\
\hline 7 & 23,03 & 26,61 & 32,16 & 21,15 & 26,45 & 26,72 & 18,18 & 26,46 & 26,16 \\
\hline 8 & 22,42 & 18,45 & 25,15 & 28,85 & 32,23 & 11,21 & 19,70 & 19,28 & 21,45 \\
\hline 9 & 6,06 & 3,86 & 7,60 & 9,62 & 5,79 & 7,76 & 10,61 & 4,48 & 6,10 \\
\hline 10 & 1,82 & 3,43 & 3,51 & 7,69 & 4,13 & 2,59 & 4,55 & 2,24 & 3,23 \\
\hline Não resposta & 13,94 & 5,15 & 6,43 & 0,00 & 0,83 & 13,79 & 22,73 & 19,73 & 10,64 \\
\hline TOTAL & 100,00 & 100,00 & 100,00 & 100,00 & 100,00 & 100,00 & 100,00 & 100,00 & 100,00 \\
\hline Desempenho Médio ${ }^{12}$ & 6,55 & 6,34 & 6,97 & 6,79 & 6,85 & 5,97 & 7,12 & 6,55 & 6,59 \\
\hline
\end{tabular}

\section{${ }^{12}$ Excluida as näo respostas}

Fonte: Caderno (2013)

\section{CONSIDERAÇÕES FINAIS}

A pesquisa realizada a pedido da diretoria do Sindicato dos Trabalhadores nas Indústrias Metalúrgicas, Mecânicas e de Material Elétrico de Criciúma e Região, antes mesmo da análise dos seus resultados, merece reconhecimento pela própria iniciativa. Em mais de 50 anos de existência, o "Sindicato dos Metalúrgicos", como é chamado popularmente, pela primeira vez toma a iniciativa de ouvir seus representados, tomar conhecimento das condições sociais, econômicas, políticas 
e, sobretudo, da realidade da formação profissional e das perspectivas de futuro da categoria. Além disto, não se tem informações de iniciativas semelhantes entre a maioria dos sindicatos de trabalhadores.

A amostra da pesquisa é consistente, com 1.147 consultas para um universo de aproximadamente 10 mil trabalhadores, e permite dados confiáveis para análises dos resultados e cruzamentos de informações. Isto fica evidenciado na prospecção da renda familiar dos entrevistados. Como os que se declararam casados ou em união estável somam 54,93\% do universo e 75,94\% têm renda

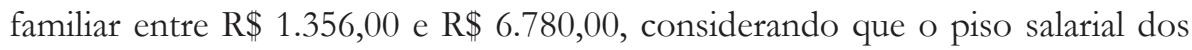
metalúrgicos, conforme as últimas convenções coletivas firmadas, é R $\$ 1.168,51$.

O nível escolar apurado é outra informação importante para o desenvolvimento de estratégias do sindicato dos trabalhadores e para instituições de ensino de toda região, somado aos dados relacionados pelos entrevistados sobre suas perspectivas de futuras qualificações profissionais. Consideradas as três primerias faixas etárias da pesquisa, que juntas totalizam trabalhadores com até 30 anos de idade, tem-se uma massa que representa 62,08\% da categoria. Dos metalúrgicos ouvidos, 916 (79,86\%) querem continuar estudando e mais de $80 \%$ integram esta faixa etária.

As avaliações sobre o interesse dos trabalhadores em relação à política partidária, do envolvimento de dirigentes sindicais nestes processos e a análise do desempenho da gestão do sindicato, da mesma forma, se tornam ferramentas importantes para definição de encaminhamentos para o cotidiano do órgão de representação dos trabalhadores nas indústrias metalúrgicas, mecânicas e de material elétrico de Criciúma e região.

Impressiona a quantidade de entrevistados rejeitando a participação dos dirigentes sindicais na atividade política partidária. Mais da metade dos entrevistados se manifestaram neste sentido em uma categoria, em tese, politizada, com forte vínculo coorporativo e mobilizada, como pode se notar em movimentos de greve e em assembleias do período de negociações coletivas.

Efetivamente, a pesquisa realizada pelo "Sindicato dos Metalúrgicos" representa um avanço na gestão e nos princípios da atividade de representar a classe trabalhadora em Criciúma e região, pois dota os dirigentes sindicais de informações valiosas para o desenvolvimento de suas atividades e merece se tornar prática mais constante no movimento sindical da região. 


\section{REFERÊNCIAS}

CADERNO dos resultados da pesquisa sobre o "Perfil e formação profissional dos funcionários da indústria metal mecânica de Criciúma e Região". CriciumaSC: Instituto de Pesquisa Socioeconômica Aplicada (Ipese) da Universidade do Extremo Sul Catarinense (Unesc), 2013.

GOULARTI FILHO, Alcides, LIVRAMENTO, Ângela Maria Antunes. Movimento operário mineiro em Santa Catarina nos anos 1950 e 1960. In: GOULARTI FILHO, Alcides (Org.) Memória e cultura do carvão em Santa Catarina. Florianópolis, Cidade Futura, 2004.

GOULARTI FILHO, Alcides. A indústria metal-mecânica no sul de Santa Catarina: uma atividade acessória e local/regional. GOULARTI FILHO, Alcides (Org.) Ensaios sobre economia sul-catarinense. Criciúma: Unesc, 2003, p, 47-57

HOBSBAWM, Eric. Era dos extremos: o breve século XX. 9. ed. São Paulo: Companhia das Letras, 1995.

HOBSBAWN, Eric J. Os Trabalhadores: Estudos sobre a história do operariado. 2.ed. São Paulo: Paz e Terra, 2000. 445 p.

HOBSBAWN, Eric J. Mundos do trabalho: novos estudos sobre história operária. 4.ed. rev. São Paulo: Paz e Terra, 2005. 460 p.

JORNAL DA MANHÃ. Criciúma, 28 de julho de 2014.

SANTOS,M.A.dos.Crescimento e CrisenaRegiãoSuldeSanta Catarina.1995. 186 p. Dissertação - UFSC -, Florianópolis, setembro, 1995. Disponível em https://repositorio.ufsc.br /xmlui/ handle/123456789/111959. Acesso em 13 de março de 2015.

Setores portadores de futuro para a indústria catarinense - 2022: estudo socioeconômico. Sistema FIESC. - Florianópolis: FIESC, 2013.

SINMETAL - Sindicato dos Trabalhadores nas Indústrias Metalúrgicas, Mecânicas e de Material Elétrico de Criciúma, 2015. Diponível em: www.sinmetal. org.br. Acesso em 16 de março 2015.

TEIXEIRA, José Paulo. Os donos da cidade. Florianópolis: Insular, 1996. 224 p. 
